\title{
Reconstitution of telomerase activity combined with HPV-E7 expression allow human preadipocytes to preserve their differentiation capacity after immortalization
}

\author{
C Darimont ${ }^{*, 1}$, I Zbinden ${ }^{1}$, O Avanti ${ }^{1}$, P Leone-Vautravers ${ }^{1}$, \\ V Giusti ${ }^{2}, P^{2}$ Burckhardt ${ }^{2}$, AMA. Pfeifer ${ }^{1}$ and $K$ Macé \\ ${ }^{1}$ Nestlé Research Center, PO Box 44, Vers-Chez-Les-Blanc, 1000 Lausanne \\ 26, Switzerland \\ 2 Département de Médecine, CHUV, Rue du Bugnon 46, 1011 Lausanne, \\ Switzerland \\ * Correspondence: C Darimont, Tel.: + 412178584 02; Fax: + 412178585 \\ 44; E-mail: christian.darimont@rdls.nestle.com
}

Received 25.11.02; revised 11.4.03; accepted 17.4.03

\begin{abstract}
Overexpression of SV40 T-antigen (SV40 T-Ag) has been widely used to overcome replicative senescence of human primary cells and to promote cell immortalization. However, in the case of certain cell types, such as preadipocytes, the differentiation process of immortalized cells is blocked by SV40 T-Ag expression. In this study, human telomerase reverse transcriptase (hTERT) and papillomavirus E7 oncoprotein (HPV-E7) genes were coexpressed in human preadipocytes to test whether this combination could maintain cell differentiation capacity after immortalization. We demonstrated that the HPV-E7/hTERT expressing preadipocytes displayed an indefinite life span. Interestingly, immortalized cells were diploid and presented no chromosomic alterations. These immortalized cells were able to accumulate and hydrolyze intracellular triglycerides and to express adipocyte markers. These data demonstrate, for the first time, that coexpression of hTERT and HPV-E7 in human preadipocytes allows cells not only to display an indefinite life span but also to retain their capacity to differentiate.
\end{abstract}

Cell Death and Differentiation (2003) 10, 1025-1031. doi:10.1038/ sj.cdd. 4401273

Keywords: oncogenes; adipogenesis; proliferation

Abbreviations: aP2, adipocyte fatty acid binding protein; BSA, bovine serum albumin; C/EBP $\alpha$, CCAAT/enhancer binding protein alpha; Dex, dexamethasone; FBS, fetal bovine serum; GPDH, glycerol-3-phosphate dehydrogenase; hTERT, human telomerase reverse transcriptase; HPV-E7, human papillomavirus E7 oncoprotein; IBMX, isobutyl methyl xanthine; LPL, lipoprotein lipase; OA, oleic acid; PPAR $\gamma$, peroxisome proliferator-activated receptor gamma; RPLp0, ribosomal protein large P0; SV40 T-Ag, SV40 T-antigen

\section{Introduction}

Proliferation of primary cells is limited to a few population doublings (PDs) before entering into a phase of growth arrest called replicative senescence. Overexpression of viral oncogenes such as the SV40 T-antigen (SV40 T-Ag) has been widely used to overcome senescence and promote human cell immortalization. ${ }^{1}$ However, ectopic expression of viral oncogenes allows primary cells to overcome replicative senescence, only for a few PDs before entering into a second nonreplicative phase called 'crisis'. ${ }^{2}$ In most cell types, rare cellular clones are able to escape from crisis and to proliferate indefinitely. ${ }^{3}$ This limitation in the immortalization process of human cells can be overcome by the reconstitution of the telomerase activity. Indeed, it has been recently shown that overexpression of the human telomerase reverse transcriptase (h-TERT) allows SV40 T-Ag-transformed cells, derived from different tissues, to bypass the crisis step and to promote indefinite life span. ${ }^{4,5}$ Nevertheless, the differentiation process of certain cell types, such as preadipocytes, is clearly blocked by SV40 T-Ag expression. ${ }^{6}$

Differentiation of preadipocytes into adipocytes (i.e. adipogenesis) is a well-described system regulated by various factors. The adipocyte differentiation cascade is controlled by two key transcriptional factors: the peroxisome proliferatoractivated receptor gamma (PPAR $\gamma$ ) and the CCAAT/enhancer binding protein alpha (C/EBP $\alpha$ ). The cAMP-response element-binding protein (CEBP) and its highly related $\mathrm{p} 300$ protein have been recently shown to be necessary for the induction of both PPAR $\gamma$ and C/EBP $\alpha .{ }^{7}$ Interestingly, SV40 T$\mathrm{Ag}$ interacts with both $\mathrm{CBP}$ and p300, inhibiting their coactivation function. ${ }^{8}$ These observations could explain why a previous attempt to immortalize human preadipocytes derived from white adipose tissue with SV40 T-Ag has failed to deliver permanent cell lines showing a preserved capacity for differentiation. ${ }^{9}$

The E7 oncoprotein from the human papillomavirus type 16 (HPV-E7) has also been reported as a factor promoting human cell immortalization. ${ }^{10}$ However, immortalization by HPV-E7 alone is a rare event. Coexpression of HPV-E7 and hTERT was shown to increase the frequency of immortalization of human keratinocytes. ${ }^{11}$ Interestingly, unlike SV40 T$\mathrm{Ag}, \mathrm{HPV}-\mathrm{E} 7$ does not bind to $\mathrm{CBP} / \mathrm{p} 300,{ }^{12}$ suggesting that overexpression of HPV-E7 in human preadipocytes could preserve their adipogenic capacity.

In this context, we tested whether ectopic expression of HPV-E7 combined with the reconstitution of telomerase activity would allow establishment of a human white preadipose cell line with an indefine life span and a preserved adipogenic capacity. For this purpose, human preadipocytes from subcutaneous white adipose tissue were successively 
infected with recombinant viruses carrying hTERT and HPVE7 genes. We showed that these transformed cells were able to proliferate indefinitely and to differentiate into lipid-filled cells expressing adipocyte markers.

\section{Results}

\section{Immortalization of human preadipocytes}

Human primary preadipocytes were infected with a recombinant retrovirus carrying the hTERT gene. Several clones were obtained after histidinol selection. These cells were able to divide until about passage 12 before entering to senescence and growth arrest (not shown). The clone presenting the best capacity to accumulate lipid was infected at passage 8 with retroviral particles containing the HPV-E7 gene. After infection, cells started to proliferate more rapidly than cells infected with hTERT alone. These cells were able to grow with a doubling time of $45.6 \pm 0.8 \mathrm{~h}$, without any modifications in cell proliferation, until at least 176 PDs (passage 46). This cell line considered as immortal was named Chub-S7. Chub-S7 cells expressed HPV-E7 gene as detected by reverse transcription-polymeral chain reaction (RT-PCR) (data not shown). Cells presented a telomerase activity (Figure 1a), which was maintained until, at least, 145 PDs (passage 38; not shown). As expected, this activity was inhibited when cell lysates were either treated with RNAse or heated (Figure 1a).

\section{Karyotype analysis}

The chromosome pattern of Chub-S7 cells, analyzed at 96 and 156 PDs (passages 25 and 41, respectively), showed that cells were diploid with $46, \mathrm{XX}$ chromosomes (Figure 1b). Chromosomes did not present any apparent abnormalities at low and high passages.

\section{Differentiation capacity of Chub-S7 cells}

To determine whether Chub-S7 cells were able to differentiate, the expression of adipocyte markers was assessed, by real-time RT-PCR, at different time points during cellular maturation induced by a PPAR $\gamma$ agonist, the BRL49653. These markers included (i) transcriptional factors involved in adipogenesis such a PPAR $\gamma$ and $\mathrm{C} / \mathrm{EBP} \alpha$, (ii) genes involved in lipid metabolism such as lipoprotein lipase (LPL) and adipocyte fatty acid binding protein (aP2), and finally (iii) adipocyte secreted factors such as adipsin and leptin.

Under basal conditions, PPAR $\gamma$ was increased by about 10fold at day 3 as compared to day 0 and remained constant until day 17. After incubation with dexamethasone (Dex) plus IBMX, PPAR $\gamma$ mRNA was increased by about 45 -fold at day 3 as compared to day 0 (Figure 2a). After IBMX removal, PPAR $\gamma$ mRNA fell to the basal level, but BRL49653 was able to reinitiate PPAR $\gamma$ expression at days 10 and 17. In the presence of $\mathrm{BRL} 49653, \mathrm{C} / \mathrm{EBP} \alpha \mathrm{mRNA}$ was slightly increased as early as day 6 after confluency and reached a plateau at day 13 (Figure 2a). The expression pattern of PPAR $\gamma$ and C/EBP $\alpha$ genes, during Chub-S7 cell differentiation, was confirmed by Western-blot analysis. As shown in a

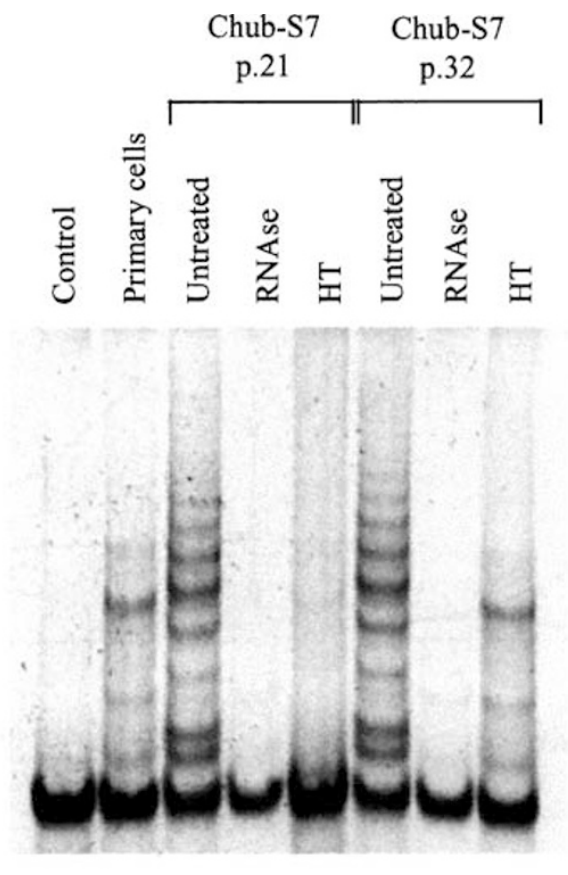

b

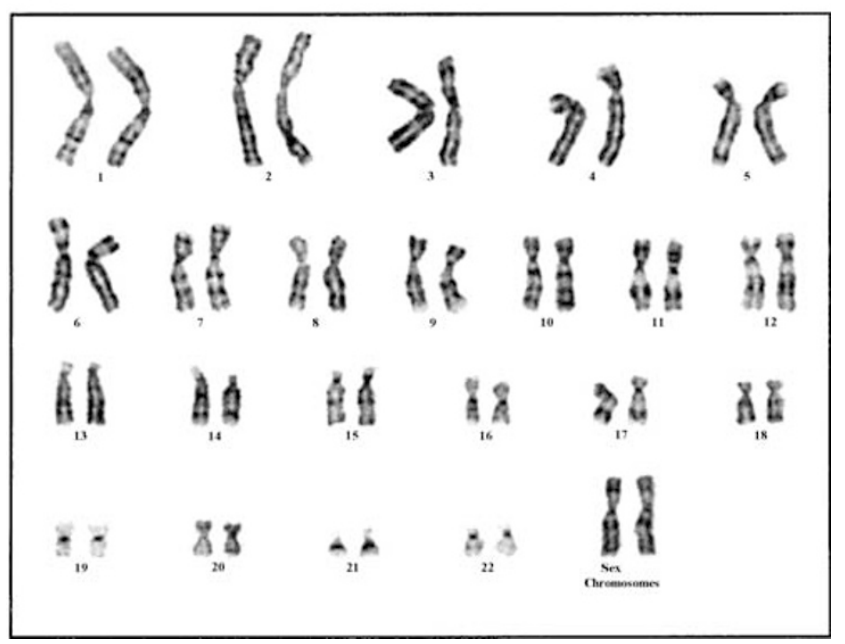

Figure 1 Telomerase activity and karyotype analysis of Chub-S7 cells. (a) Telomerase activity was measured on (i) lysis buffer alone (control), (ii) homogenates of preadipocytes before infections (primary cells), and (iii) homogenates of confluent Chub-S7 cells (passages 21 and 32 corresponding to 80 and 122 PDs) treated or not with RNAse (RNAse) or heated (HT). (b) The cytogenetic analysis was performed on Chub-S7 cells at 96 PDs as indicated in Material and Methods

Figure $2 b$, the expression of both proteins was time dependent with a maximum level observed at day 17 .

Cells cultured in the presence of the PPAR $\gamma$ agonist showed increased levels of aP2 and LPL mRNA as early as days 3 and 6 after confluency, respectively (Figure 3 ). This expression continued to increase up to day 17 for both genes. Dex alone was able to enhance aP2 and LPL mRNA expression significantly at day 17 as compared to day 0 , but to a lesser extent to that observed in the presence of the PPAR $\gamma$ agonist (5 versus 5400 -fold increase for aP2 and 8 versus 150 -fold increase for LPL). 
a

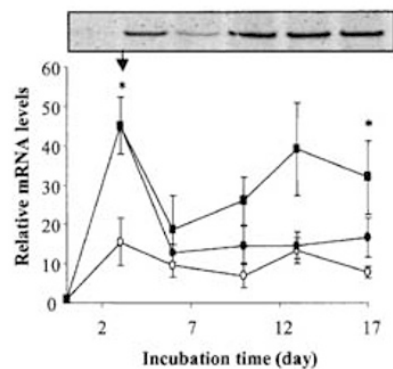

b

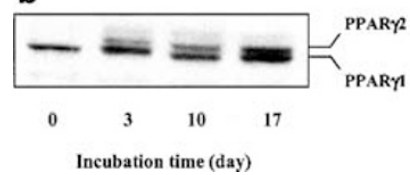

$\mathrm{C} / \mathrm{EBP} \alpha$
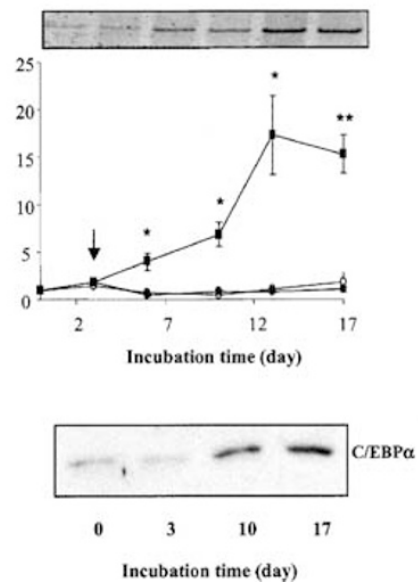

Figure 2 Profile of PPAR $\gamma$ and $\mathrm{C} / \mathrm{EBP} \alpha$ gene and protein expression during Chub-S7 cell differentiation. (a) Chub-S7 cells were cultured in the presence of the basal medium alone $(O)$, or supplemented with Dex plus IBMX from days 0 to 3 and Dex alone from days 3 to $17(\mathbf{O})$ or with BRL49653 ( $)$. The arrow indicates the day from which BRL49653 was added to the medium. Relative gene expression was quantified by real-time RT-PCR. Data are the means \pm s.e.m. of values obtained at least in four separate experiments. Values significantly different from the basal conditions at defined days during the time course are indicated by ${ }^{*}(P<0.05)$ or ${ }^{* *}(P<0.01)$. Top panels show representative RT-PCRs performed at a number of cycles defined according to the linear amplification of the genes (see Material and Methods). (b) PPAR $\gamma$ and $\mathrm{C} / \mathrm{EBP} \alpha$ proteins were detected in lysates of Chub-S7 cells at different stages of differentiation. These Western blots are representative of two independent experiments

Adipsin mRNA levels reached a plateau as early as day 10 , whereas the highest leptin mRNA expression was observed only at day 17 (Figure 3). Before day 17, the increase in leptin mRNA was similar in the presence or absence of the PPAR $\gamma$ agonist but was two-fold higher at day 17 in the presence of BRL49653 when compared to Dex alone. The expression of the ribosomal protein large P0 (RPLpO) used in this study for normalization showed no changes in mRNA levels during Chub-S7 cell differentiation (Figure 3 ).

These results show that under conventional serum-free culture conditions, differentiated Chub-S7 cells were able to acquire the main adipocyte markers.

\section{Functional characteristics of differentiated Chub- S7 cells}

To study the ability of differentiated Chub-S7 cells to accumulate intracellular lipids, cells cultured for 17 days in the absence or presence of BRL49653 were fixed and stained with Oil-red $\mathrm{O}$. Almost all the differentiated cells were able to accumulate at least one single lipid droplet and few of them presented large multilocular droplets (Figure 4a). When oleic acid (OA) (100 $\mu \mathrm{M}$ complexed with $\mathrm{BSA}$ ) was added from days 10 to 17 to the differentiation medium containing BRL49653, Chub-S7 cells showed a dramatic increase in their triglyceride content with large multilocular lipid droplets (Figure 4a). The presence of OA did not affect the expression of LPL, C/EBP $\alpha$,

aP2, leptin and adipsin induced by BRL49653 (data not shown).

Lipolytic capacity of differentiated cells was assessed by measuring glycerol release, after stimulation or not for $1 \mathrm{~h}$ with $1 \mu \mathrm{M}$ isoproterenol (Iso), a nonspecific $\beta$-adrenergic agonist. Cells were differentiated in the presence of BRL49653 alone. Iso significantly increased by $40.5 \%$ lipolysis in cells cultured in the presence of the PPAR $\gamma$ agonist (Figure $4 \mathrm{~b}$ ).

The glycerol-3-phosphate dehydrogenase (GPDH) is a key enzyme involved in the glycerol phosphate shuttle pathway. Its activity was measured in Chub-S7 cells during differentiation. Figure 4c shows that GPDH-specific activity was slightly increased, at day 10, in the presence of BRL49653 and reached a maximum level at day 17 . Under basal conditions or with Dex alone, GPDH specific activity was not increased along the time course (Figure 4c).

\section{Discussion}

SV40 T-Ag, a well-known immortalizing factor, has been shown to alter cell differentiation and especially to block the maturation of preadipocytes into adipocytes. ${ }^{6}$ This inhibitory effect of SV40 T-Ag could explain the limited differentiation capacity of the SV40 T-Ag-transformed human white preadipocytes described previously. ${ }^{9}$ In this study, we demonstrate, for the first time, that co-expression of hTERT and HPV-E7 in human preadipocytes allows cells not only to display an indefinite life span but also to retain their features of primary cells. The immortalized Chub-S7 cells displayed a comparable proliferation rate and a similar doubling time to human primary stromal cells, ${ }^{13}$ suggesting a limited deregulation of cell cycle checkpoints. In the presence of fatty acids, the differentiated Chub-S7 cells were able to accumulate large lipid droplets, indicating a preserved capacity to synthesize triglycerides. On the other hand, when Chub-S7 cells were differentiated in the presence of carbohydrates as a unique substrate for triglyceride synthesis, a reduced lipid droplet accumulation was observed. Interestingly, HPV-E7 was described to inhibit pyruvate kinase, a rate-limiting enzyme of the glycolytic pathway. ${ }^{14}$ This HPV-E7 property could explain the limited capacity of Chub-S7 cells to synthetize lipids from glucose (i.e. de novo lipogenesis). Nevertheless, in human adipose tissue, lipogenesis is a minor pathway for triglyceride synthesis as compared to fatty acid esterification, ${ }^{15}$ indicating that Chub-S7 cell metabolism is close to the in vivo situation. Finally, the lipid filled Chub-S7 cells were able to hydrolyze intracellular triglycerides under basal or stimulated conditions by a $\beta$-adrenergic receptor agonist, indicating a functional lipolytic activity.

The preserved phenotype observed in Chub-S7 cells when compared to SV40 T-Ag expressing human or mouse white preadipocytes $^{6,9}$ could be explained by differences in the (i) genomic stability and/or (ii) interaction of the viral oncogenes with adipogenic factors. (i) The chromosomal aberrations, generally observed in immortalized cells, ${ }^{16}$ can be responsible for important phenotypic changes. Cytogenic analysis showed that Chub-S7 cells retained a remarkable diploid feature without apparent chromosome aberrations, even at high passages. The fact that hTERT was introduced first in the 
Adipsin

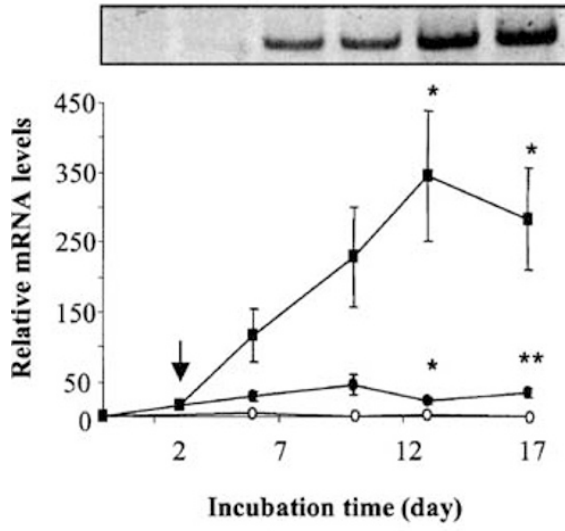

LPL

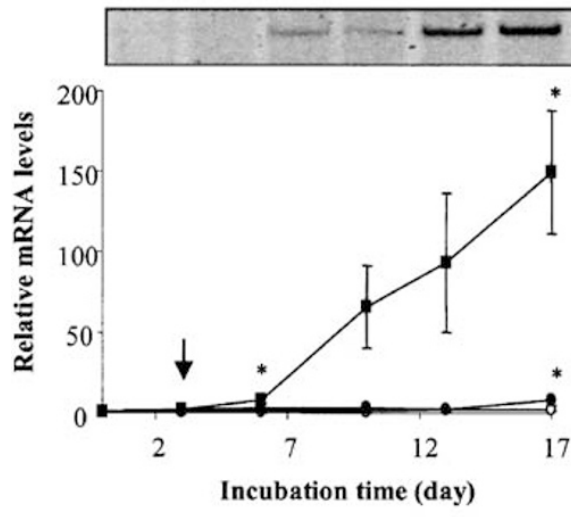

\section{Leptin}

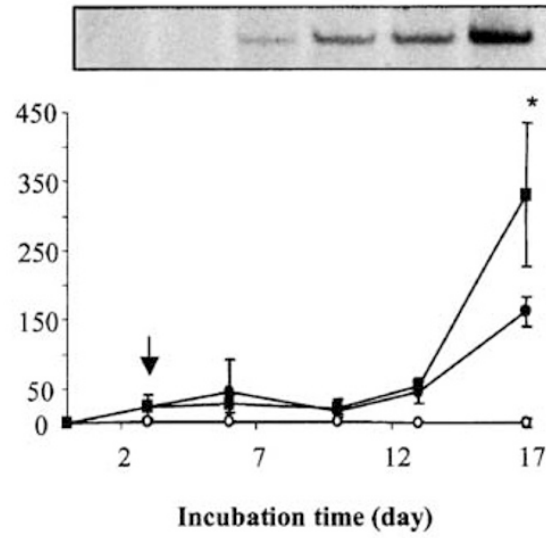

aP2

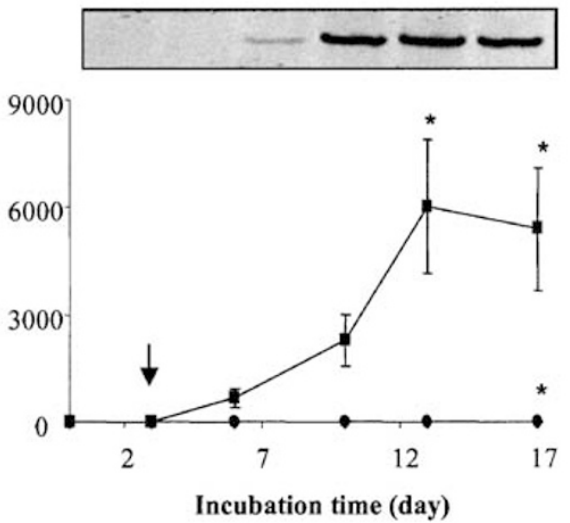

RPL-P0

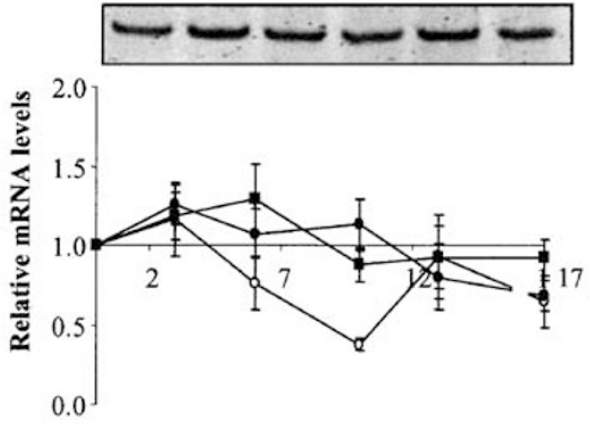

Incubation time (day)

Figure 3 Profile of LPL, aP2, adipsin leptin, and RPL-P0 gene expression during Chub-S7 cell differentiation. See legend to Figure 2a

human preadipocytes, which were later transformed with HPV-E7, may have positively influenced the genomic stability of Chub-S7 cells. The function of telomerase on telomere maintenance that protects chromosomes from exonucleolytic degradation could account for the genomic stability ${ }^{17}$ and preserved phenotype observed in Chub-S7 cells. This has been previously demonstrated in mammary fibroblasts where the introduction of hTERT first and then SV40-T Ag yielded diploid cell lines, whereas introduction of hTERT late after the viral oncogene induced aneuploidy. ${ }^{18}$ (ii) Viral oncogenes are known to interact with different cell cycle proteins such as the tumor suppressor protein p53 and retinoblastoma protein (pRb) family, including pRb, p107 and p300 members. SV40 $\mathrm{T}-\mathrm{Ag}$, but not HPV-E7, inactivates p53, while both viral oncogenes have been reported to interact with the $\mathrm{pRb}$ family. ${ }^{19}$ Among this protein family, $\mathrm{pRb}$ inactivation but not p107 was reported to block adipocyte differentiation. ${ }^{20}$ The fact that Chub-S7 cells retained the capacity to differentiate 
a

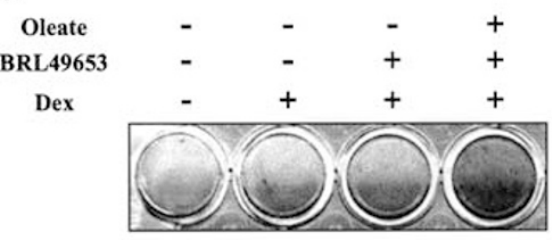

Dex + BRL49653

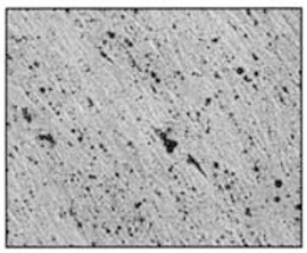

b

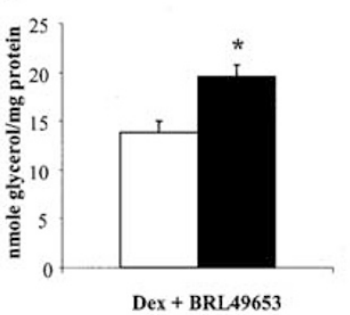

Dex + BRL49653 + Oleate

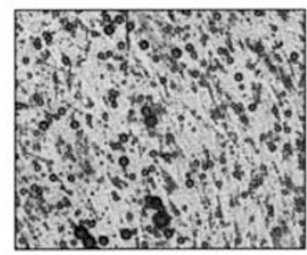

c

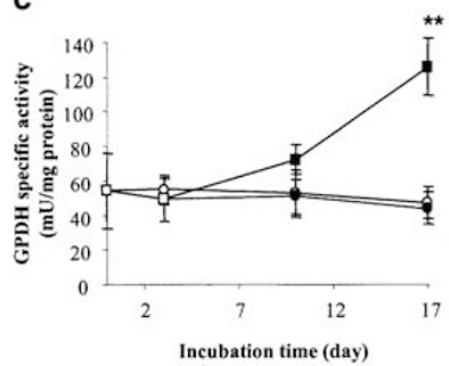

Figure 4 Characteristics of differentiated Chub-S7 cells. (a) Triglyceride accumulation: Chub-S7 cells were differentiated in the presence of basal medium alone, or supplemented with Dex, or Dex plus BRL49653 or Dex plus BRL49653 plus OA. At day 17 , cells were fixed and triglycerides were visualized using the Oil-red $O$ staining. The morphology of Chub-S7 cells differentiated with Dex and BRL49653 or in the same medium supplemented with OA is presented in the two micrographs (magnitude X400). Data are representative of at least three independent experiments. (b) lipolysis Chub-S7 cells were differentiated in the presence of Dex plus BRL49653. Glycerol released was measured at day 17 in the culture medium of cells incubated in the presence (black bar) or in the absence (white bar) of $1 \mu \mathrm{M}$ isoproterenol. Data are the means of values obtained in at least four separate experiments. Values significantly different from the basal condition (white bar) are indicated by * $(P<0.05)$. (c) GPDH activity Chub-S7 cells were cultured in the presence of the basal medium alone $(O)$, or supplemented with $\operatorname{Dex}(\boldsymbol{O})$ or with Dex and BRL49653 ( $\mathbf{\square})$. GPDH activity was measured at day 17 as described in Materials and Methods. Data are the means \pm s.e.m. of values obtained in at least four separate experiments. Values significantly different from the basal condition at defined days during the time course are indicated by ${ }^{* *}(P<0.01)$

can be explained by the greater binding of HPV-E7 on p107 than $p R b$, whereas SV40 T-Ag interacts equivocally with $p R b$, $\mathrm{p} 107$, and $\mathrm{p} 130 .^{21}$ This hypothesis is reinforced by the observation that unlike mouse preadipocytes lacking $\mathrm{pRb},{ }^{20}$ $\mathrm{C} / \mathrm{EBP} \alpha$ gene, an important transcription factor involved in the process of adipocyte differentiation, was expressed during Chub-S7 cell differentiation. Finally, another pathway, than those involving the $\mathrm{pRb}$ family, could explain the preserved adipogenic capacity of Chub-S7 cells. As previously mentioned, unlike SV40 T-Ag, HPV-E7 does not interact with the $\mathrm{CBP} / \mathrm{p} 300$ transcriptional complex, ${ }^{12}$ which has been recently described to be necessary for the induction of both PPAR $\gamma$ and $\mathrm{C} / \mathrm{EBP} \alpha$.

Owing to a higher replication rate of preadipocytes derived from massively obese subjects, ${ }^{22}$ the use of adipocyte precursors from subcutaneous abdominal adipose tissue of a subject with a BMl of $54 \mathrm{~kg} / \mathrm{m}^{2}$ could have facilitated the immortalization process. Nevertheless, our immortalization strategy does not appear to be specific of fat depots, since we have recently obtained a preadipose cell line derived from omental adipose tissue of the same subject. These cells were able to grow until at least 60 PDs and preliminary data indicated a preserved phenotype and adipogenic capacity as observed in their subcutaneous counterparts, the Chub-S7 cells (data not shown).

In conclusion, we show that preadipocytes derived from human white adipose tissue preserved their adipogenic capacity after immortalization by hTERT and HPV-E7 coexpression. This approach allowed, for the first time, the establishment of a human white preadipose cell line, which represents a useful model for studying pharmacological and nutritional regulations of adipocyte differentiation and metabolism.

\section{Materials and Methods}

\section{Materials}

Cell culture media, fetal bovine serum (FBS) and Hepes buffer were purchased from Gibco BRL (Basel; Switzerland). Fetuin, transferrin, histidinol, insulin, triiodothyronin, Dex, isobutyl methyl xanthine (IBMX), biotin, D-panthotenic acid, OA were purchased from Sigma (Buchs; Switzerland). $\mathrm{NaHCO}_{3}$ was obtained from Merck (Darmstadt; Germany).

\section{Recombinant virus preparation}

Infectious hTERT recombinant viral particles were generated as previously described. ${ }^{5}$ The packaging cell line PA317 transfected with a retroviral construct consisting of the $\mathrm{pLXSN}$ vector containing the HPV-E7 gene was kindly provided by $\mathrm{Dr}$. CC Harris ( $\mathrm{NCl}, \mathrm{NIH}$, Bethesda, USA). Viral particles were obtained through the ping-pong procedure as previously described. $^{23}$

\section{Preparation and infection of human preadipocytes}

Adipocyte precursors from subcutaneous abdominal adipose tissue obtained during a gastroplasty surgery of a 33-year-old obese female patient, with a body mass index of $54 \Omega \mathrm{g} / \mathrm{m}^{2}$, were prepared as previously described $^{24}$ and cultivated in a mix of DMEM/F12 media (v/v) supplemented with $2 \mathrm{mM}$ glutamine, $100 \mathrm{U} / \mathrm{ml}$ penicillin/streptamycin and $10 \%$ FBS. At $70-80 \%$ confluence, primary preadipocytes were incubated for $4 \mathrm{~h}$ at $37^{\circ} \mathrm{C}$ and $5 \% \mathrm{CO}_{2}$ with recombinant retrovirus containing the hTERT gene in the presence of $20 \mu \mathrm{g} / \mathrm{ml}$ DEAE dextran. After infection, the culture medium was changed to a mixture of DMEM/ F12 media supplemented with 10\% FBS, glutamine and penicillin/streptomycin. After $48 \mathrm{~h}, 5 \mathrm{mM}$ histidinol was added to the culture medium and viable clones were isolated and expanded. Their ability to differentiate into lipid-filled adipocytes was tested using the Oil-red $O$ staining, as described below. The clone presenting the highest lipid accumulation was grown until passage 8 and infected with a recombinant virus containing the HPV-E7 gene. 


\section{Differentiation of Chub-S7 cells}

Cells were grown in a mixture of DMEM/F12 media supplemented with $10 \%$ FBS, $2 \mathrm{mM}$ glutamine, $100 \mathrm{U} / \mathrm{ml}$ penicillin/streptamycin until confluency. For differentiation, cells were cultured with a serum-free medium consisting of a mixture of DMEM/F12 media supplemented with $15 \mathrm{mM} \mathrm{NaHCO}_{3}, 17 \mu \mathrm{M}$ D-panthotenic acid, $15 \mathrm{mM}$ Hepes, $33 \mu \mathrm{M}$ biotin, $10 \mu \mathrm{g} / \mathrm{ml}$ transferrin, $1 \mathrm{nM}$ triiodothyronin, $850 \mathrm{nM}$ insulin and $500 \mu \mathrm{g} / \mathrm{ml}$ fetuin. This medium, referred to as 'basal medium', was supplemented with $1 \mu \mathrm{M}$ Dex and $500 \mu \mathrm{M}$ IBMX from day 0 to 3 . Dex was maintained alone or with $1 \mu \mathrm{M}$ BRL49653 from day 3 to 17 in order to promote differentiation. As stated in Results, OA complexed with bovine serum albumin (BSA; ratio OA-to-BSA: 5:1) was added to the medium containing BRL49653 from days 10 to 17. Lipid accumulation in differentiated cells was visualized by Oil-red $O$ staining as previously described. ${ }^{13}$ All the experiments on Chub-S7 cell characterization were performed between passages 18 and 32 (69-122 PDs).

\section{GPDH activity and lipolysis measurements}

GPDH activity measured at different times during the differentiation process of Chub-S7 cells was determined using an enzymatic assay previously described. ${ }^{13}$ Lipolysis was determined at day 17 after confluency. Cells were incubated $1 \mathrm{~h}$ at $37^{\circ} \mathrm{C}$ and $5 \% \mathrm{CO}_{2}$ with a Krebs-Ringer buffer $\left(5 \mathrm{mM} \mathrm{NaH}_{2} \mathrm{PO}_{4} ; 1 \mathrm{mM} \mathrm{MgSO}\right.$; $1 \mathrm{mM} \mathrm{CaCl}$; $136 \mathrm{mM} \mathrm{NaCl} ; 4.7 \mathrm{mM} \mathrm{KCl}$ ) supplemented with $20 \mathrm{mM}$ Hepes, $2 \% \mathrm{BSA}$, $5 \mathrm{mM}$ glucose and $1 \mu \mathrm{M}$ isoproterenol as indicated in Results. Glycerol released in the medium was measured using the glycerokinase enzymatic radiometric assay described by Bradley and Kaslow. ${ }^{25}$

\section{Telomerase repeat amplification (TRAP) assay}

$10^{6}$ cells, corresponding to about $100 \mu \mathrm{g}$ proteins, were homogenated in lysis buffer (10 mM Tris- $\mathrm{HCl}, \mathrm{pH} 7.5,1 \mathrm{mM} \mathrm{MgCl}, 1 \mathrm{mM}$ EGTA, $0.5 \%$ CHAPS, $10 \%$ glycerol). The TRAP reaction was performed using $2 \mu \mathrm{g}$ of protein extracts as previously described. ${ }^{5} 20 \mu$ of the reaction mixture $(50 \mu l)$ was loaded on a $10 \%$ acrylamide gel for the visualization of telomeric repeat amplifications. To assess the specificity of the RNAdependent enzymatic reactions, extracts inhibited by RNAse or heat treatment were included. For RNAse treatment, protein extracts were incubated with $1 \mu \mathrm{g}$ RNAse A (Roche Diagnostics, Switzeerland) at $37^{\circ} \mathrm{C}$ for $20 \mathrm{~min}$, and for heat treatment, the homogenates were incubated for $10 \mathrm{~min}$ at $85^{\circ} \mathrm{C}$.

\section{Karyotype analysis}

Semiconfluent cultures were sent to the Cell Culture Laboratory (Children's Hospital of Michigan, MI, USA) for karyotyping analysis performed as previously described. ${ }^{5}$

\section{Analysis of adipocyte markers expression}

RNAs from Chub-S7 cells cultured from day 0 to 17 were extracted using the NucleoSpin ${ }^{\circledR}$ Total RNA Purification System (Macherey-Nagel, Oensingen Switzerland). Reverse transcription was performed with an input of $10 \mu \mathrm{g}$ of total RNA using the first strand CDNA synthesis kit for RTPCR (AMV; Roche Biomedical, Basel, Switzerland) with oligo d(T) $)_{15}$ as primer. Real-time RT-PCR analyses were performed in a fluorescent temperature cycler (GeneAmp ${ }^{\circledR}$ PCR 5700 Sequence Detection System; Applied Biosystem) according to the recommendations of the manufac- turer. Briefly, after initial denaturation at $50^{\circ} \mathrm{C}$ for $2 \mathrm{~min}$ and $95^{\circ} \mathrm{C}$ for $10 \mathrm{~min}$, reactions were cycled 40 times using the following parameters for all genes studied: $95^{\circ} \mathrm{C}$ for $15 \mathrm{~s}$, primer annealing and extension at $60^{\circ} \mathrm{C}$ for $1 \mathrm{~min}$. SYBR Green I fluorescence was detected at the end of each cycle to monitor the amount of PCR product formed during that cycle. Primers used for the amplification of CDNAs of interest were synthesized by Mycrosynth (Windisch, Switzerland). The sequence of the forward and reverse primers was, respectively: $5^{\prime}$-GCAACAAAGTCCCGAGCAA- $3^{\prime}$ and $5^{\prime}$-CCTTCTGCATATAGTAGGTGCTCAAT-3' for the adipsin gene, 5'-AAACTGGTGGTGGAATGCG-3' and $5^{\prime}$-CCCTTGGCTTATGCTCT CTCA-3' for the Ap2 gene, $5^{\prime}$-ACTGGGACCCTCAGCCTTG- $3^{\prime}$ and 5'-TGGACTGATCGTGCTTCGTG-3' for the C/EBP $\alpha$ gene, 5'-CCA GAAACGTGATCCAAATATCC-3' and 5'-GAAGGCCAGCACGTGAA GA-3' for the leptin gene, $5^{\prime}$-TGCCCTAAGGACCCCTGAA- $3^{\prime}$ and $5^{\prime}$-CAGGTAGCCACGGACTCTGC-3' for the LPL gene, 5'-CAAACAC ATCACCCCCCTG-3' and $5^{\prime}$-AAACTGGCAGCCCTGAAAGA-3' for the PPAR $\gamma$ gene, and 5'-CCACGCTGCTGAACATGCT-3' and 5'-TCG AACACCTGCTGGATGAC-3' for the RPL-p0 gene, cycle-to-cycle fluorescence emission was monitored and quantified using the GenAmp software provided by Applied Biosystem. Relative mRNA levels $\left(2^{\Delta \mathrm{Ct}}\right)$ were determined by comparing the PCR cycle threshold $(\mathrm{Ct})$ between cells at days 0 and cells at days $6,10,13$ and 17 after confluency $(\Delta \mathrm{Ct})$. At day 0 , all the genes studied had a detectable amplification level before the 40 cycles of the real-time PCR, with Ct values significantly lower than the $\mathrm{Ct}$ obtained in the absence of cDNA (not shown). The purity of the PCR products was checked by analyzing melting curves. The specificity of the amplification product was verified by performing a PCR under the conditions described above, but during a number of cycles defined according to the linear amplification of the genes (number of cycles for the amplification of adipsin: 23; aP2: 20; C/EBP $\alpha$ : 25; Leptin: 29; LPL: 28; PPAR $\gamma ; 23)$. The PCR products were subjected to electrophoresis on a $12 \%$ acrylamide gel followed by staining with Sybergold (Molecular probes, Leiden, The Netherlands).

\section{Western-blot analysis}

Cell homogenates $(25 \mu \mathrm{g})$ prepared as previously described ${ }^{26}$ were electrophoresed and transferred to Immobilon polyvinylidene difluoride membranes (Millipores, Switzerland). Membranes were hybridized with anti-PPAR $\gamma$ primary antibody (cat. no. sc-7273, mouse monoclonal IgG, Santa Cruz Biotchnology) or anti-C/EBP $\alpha$ primary antibody (cat. no. sc-61, rabbit polyclonal IgG Santa Cruz Biotechnology) both diluted $1: 200$, for $4 \mathrm{~h}$ at room temperature. Antigen-antibody complexes were detected by incubating immunoblots with secondary antibodies labeled with horseradish peroxidase, and revealed by chemiluminescence $(E C L$, Western blotting detection system, Amersham Life Science). Owing to an unspecific binding of the $\mathrm{C} / \mathrm{EBP} \alpha$ primary antibody to an antigen migrating at the same level as the $42 \mathrm{KDa} C E B P \alpha$ isoform, only the $30 \mathrm{KDa}$ isoform was shown in Figure $2 b$.

\section{Statistical analysis}

Statistical comparisons were performed on absolute values by ANOVA.

\section{Acknowledgments}

We are grateful to Dr CC Harris (National Institutes of Health, Bethesda, USA) for the HPV-E7 recombinant retrovirus and Dr. EA Offord (Nestlé 
Research Center, Lausanne, Switzerland) for critically reading the manuscript.

\section{References}

1. Jha KK, Banga S, Palejwala V and Ozer HL (1998) SV40-mediated immortalization. Exp. Cell Res. 245: 1-7

2. Shay JW, Wright WE and Werbin H (1991) Defining the molecular mechanisms of human cell immortalization. Biochim. Biophys. Acta. 1072: 1-7

3. Huschtscha LI and Holliday R (1983) Limited and unlimited growth of SV40transformed cells from human diploid MRC-5 fibroblasts. J. Cell Sci. 63: 77-99

4. Halvorsen TL, Leibowitz $G$ and Levine $F$ (1999) Telomerase activity is sufficient to allow transformed cells to escape from crisis. Mol. Cell Biol. 19: 1864-1870

5. Darimont C, Avanti O, Tromvoukis Y, Vautravers-Leone P, Kurihara N Roodman GD, Colgin LM, Tullberg-Reinert H, Pfeifer AM, Offord EA and Mace $\mathrm{K}$ (2002) SV40 T antigen and telomerase are required to obtain immortalized human adult bone cells without loss of the differentiated phenotype. Cell Growth Differ. 13: 59-67

6. Cherington V, Brown M, Paucha E, St Louis J, Spiegelman BM and Roberts TM (1988) Separation of simian virus 40 large-T-antigen-transforming and originbinding functions from the ability to block differentiation. Mol. Cell Biol. 8: 13801384

7. Erickson RL, Hemati N, Ross SE and MacDougald OA (2001) p300 coactivates the adipogenic transcription factor CCAAT/enhancer-binding protein alpha. J. Biol. Chem. 276: 16348-16355

8. Lill NL, Grossman SR, Ginsberg D, DeCaprio J and Livingston DM (1997) Binding and modulation of p53 by p300/CBP coactivators. Nature 387 : 823-827

9. Forest C, Czerucka D, Negrel R and Ailhaud G (1983) Establishment of a human cell line after transformation by a plasmid containing the early region of the SV40 genome. Cell. Biol. Int. Rep. 7: 73-81

10. Zwerschke $W$ and Jansen-Durr $P(2000)$ Cell transformation by the $E 7$ oncoprotein of human papillomavirus type 16: interactions with nuclear and cytoplasmic target proteins. Adv. Cancer Res. 78: 1-29

11. Kiyono T, Foster SA, Koop Jl, McDougall JK, Galloway DA and Klingelhutz AJ (1998) Both Rb/p16INK4a inactivation and telomerase activity are required to immortalize human epithelial cells. Nature 396: $84-88$

12. Huang SM and McCance DJ (2002) Down regulation of the interleukin-8 promoter by human papillomavirus type $16 \mathrm{E} 6$ and $\mathrm{E} 7$ through effects on $\mathrm{CREB}$ binding protein/p300 and P/CAF. J. Virol. 76: 8710-8721

13. Wabitsch M, Brenner RE, Melzner I, Braun M, Moller P, Heinze E, Debatin KM and Hauner $\mathrm{H}$ (2001) Characterization of a human preadipocyte cell strain with high capacity for adipose differentiation. Int. J. Obes. Relat. Metab. Disord. 25: 8-15

14. Zwerschke W, Mazurek S, Massimi P, Banks L, Eigenbrodt E and Jansen-Durr P (1999) Modulation of type M2 pyruvate kinase activity by the human papillomavirus type 16 E7 oncoprotein. Proc. Natl. Acad. Sci. USA 96: 1291-1296

15. Shrago E and Spennetta T (1976) The carbon pathway for lipogenesis in isolated adipocytes from rat, guinea pig, and human adipose tissue. Am. J. Clin. Nutr. 29: 540-545

16. Ray FA, Peabody DS, Cooper JL, Cram LS and Kraemer PM (1990) SV40T antigen alone drives karyotype instability that precedes neoplastic transformation of human diploid fibroblasts. J. Cell. Biochem. 42: 13-31

17. Liu JP (1999) Studies of the molecular mechanisms in the regulation of telomerase activity. FASEB J. 13: 2091-2104

18. O'Hare MJ, Bond J, Clarke C, Takeuchi Y, Atherton AJ, Berry C, Moody J, Silver AR, Davies DC, Alsop AE, Neville AM and Jat PS (2001) Conditional immortalization of freshly isolated human mammary fibroblasts and endothelial cells. Proc. Natl. Acad. Sci. USA 98: 646-651

19. Hickman ES, Bates S and Vousden KH (1997) Perturbation of the p53 response by human papillomavirus type $16 \mathrm{E} 7$. J. Virol. 71 : 3710-3718

20. Classon M, Kennedy BK, Mulloy R and Harlow E (2000) Opposing roles of pRB and p107 in adipocyte differentiation. Proc. Natl. Acad. Sci. USA 97: 10826-10831

21. Smith-McCune $K$, Kalman D, Robbins $C$, Shivakumar $S$, Yuschenkoff $L$ and Bishop JM (1999) Intranuclear localization of human papillomavirus 16 E7 during transformation and preferential binding of $\mathrm{E} 7$ to the $\mathrm{Rb}$ family member p130. Proc. Natl. Acad. Sci. USA 96: 6999-7004

22. Roncari DA, Lau DC and Kindler S (1981) Exaggerated replication in culture of adipocyte precursors from massively obese persons. Metabolism 30: 425-427

23. Pfeifer AMA, Macé K, Tromvoukis $Y$ and Lipsky MM (1995) Highly efficient establishment of immortalized cells from adult human liver. Methods Cell Science 17: 83-89

24. Sugihara H, Yonemitsu N, Miyabara S and Yun K (1986) Primary cultures of unilocular fat cells: characteristics of growth in vitro and changes in differentiation properties. Differentiation 31: 42-49

25. Bradley DC and Kaslow HR (1989) Radiometric assays for glycerol, glucose, and glycogen. Anal. Biochem. 180: 11-16

26. Tchkonia T, Giorgadze N, Pirtskhalava T, Tchoukalova $Y$, Karagiannides I, Forse RA, DePonte M, Stevenson M, Guo W, Han J, Waloga G, Lash TL, Jensen MD and Kirkland JL (2002) Fat depot origin affects adipogenesis in primary cultured and cloned human preadipocytes. Am. J. Physiol. Regul. Integr. Comp. Physiol. 282: R1286-R1296 